\title{
The use of vitamin $D$ in depression
}

\author{
Klaus W. Lange*, Katharina M. Lange, Yukiko Nakamura and Andreas Reissmann
}

Department of Experimental Psychology, University of Regensburg, Regensburg, Germany

*Corresponding author: Klaus W. Lange, Institute of Psychology, University of Regensburg, 93040 Regensburg, Germany. Tel: +49 941 9433815; Fax: +49 941 9434496; E-mail: klaus.lange@ur.de

DOI: $10.31665 /$ JFB. 2021.15278

Received: September 22, 2021; Revised received \& accepted: September 29, 2021

Citation: Lange, K.W., Lange, K.M., Nakamura, Y., and Reissmann, A. (2021). The use of vitamin D in depression. J. Food Bioact. 15: $13-20$.

\begin{abstract}
Vitamin D has increasingly been associated with the pathophysiology of mental illness and has been suggested to have beneficial effects on depression in adults. Epidemiological studies concerning vitamin $D$ and depression have found inconsistent results and many have significant methodological limitations. The available evidence suggests that depressed individuals show reduced vitamin D concentrations compared to controls without depression. Despite the available findings suggesting that hypovitaminosis $D$ elevates the risk of depressive mood, the evidence of observational and interventional studies is insufficient to establish causality between low vitamin $D$ levels and the occurrence of depression. The question of whether vitamin D sufficiency has protective efficacy against incident depression or recurrence requires future investigation. In order to examine the therapeutic efficacy of vitamin D, further well-designed, large-scale, long-term intervention trials of vitamin D supplementation in people of different age groups with depressive symptoms, diagnosed depression, postpartum depression or other depressive disorders are warranted. In short, current evidence cannot definitively establish whether vitamin D deficiency is a risk factor in the development of depression or whether vitamin D is effective in the treatment of depression.
\end{abstract}

Keywords: Vitamin D; Depression; Mood; Epidemiology; Treatment.

\section{Introduction}

Depression is globally a highly prevalent mental disorder that can occur across the entire lifespan (Kessler et al., 2007). The 12-month prevalence of major depressive disorder has been estimated to be approximately $6 \%$ (Kessler and Bromet, 2013), with a lifetime risk of 15-18\% (Bromet et al., 2011). Major depressive disorder has been predicted to become the leading global cause of disease burden by 2030 (Kessler et al., 2003; World Health Organization, 2008). Major depressive disorder is characterized by depressed mood, anhedonia, reduced self-esteem and fatigue (American Psychiatric Association, 2013) and can cause significant functional disability and severely limit the psychosocial functioning and quality of life of those affected (Malhi and Mann, 2018). Both depressive disorders and subthreshold depressive symptoms have been found to be associated with considerable disability, health care costs and mortality (Broadhead et al., 1990; Pietrzak et al.,
2013). While a biopsychosocial model of the etiology of depression has been proposed, with biological, psychological, social and environmental factors contributing to the development of depression, the pathophysiological mechanisms underlying depression remain largely unknown (Krishnan and Nestler, 2010).

The treatment of major depressive disorder, with its high rate of recurrence, remains difficult and less than satisfactory (Malhi and Mann, 2018). While pharmacotherapy and/or cognitive behavior psychotherapy have been demonstrated to be efficacious in the treatment of depression (Cuijpers et al., 2008; Cuijpers et al., 2009), some degree of non-response to antidepressant medications may occur in up to $60 \%$ of individuals with major depressive disorder (Bschor and Baethge, 2010; Fava, 2003). Almost a third of people treated for depression remain refractory to multistep antidepressant therapies (Rush et al., 2006a; Rush et al., 2006b), and the long-term effectiveness of pharmacotherapy and psychotherapy remains a matter of debate (Casacalenda et al., 2002). Moreover, 
poor acceptability of treatment (Jorm, 2000) and adverse effects of antidepressant drugs (Anderson et al., 2012; Goethe et al., 2007) may result in discontinuation of treatment. The need for the development of further medications and novel approaches to the prevention and treatment of depression has therefore been emphasized (Insel, 2015; Miller, 2010).

Diet and nutrition have been found not only to be critically involved in the promotion of metabolic health (Bennett et al., 2015), but also to play a role in mental health and to be capable of modifying mental disorders (Lange, 2018; Lange, 2020a; Marx et al., 2017). The risk of depression appears to be inversely associated with the Mediterranean diet (Lai et al., 2014; Opie et al., 2015; Psaltopoulou et al., 2013), while Western diets have been reported to be positively correlated with depression (Lai et al., 2014). Various food bioactives, such as omega-3 polyunsaturated fatty acids (Lange, 2020b; Lange, 2021; Lange et al., 2021a), probiotics (Lange et al., 2020) and L-theanine and epigallocatechine gallate (Lange et al., 2021b) have shown associations with depression risk. Emerging evidence suggests that vitamin D deficiency is also linked to depression, with people showing normal vitamin D levels having a reduced risk of developing depression (e.g. Anglin et al., 2013; Black et al., 2014; Brouwer-Brolsma et al., 2015; Hoogendijk et al., 2008; Kerr et al., 2015; von Känel et al., 2015). These findings have led to investigations of food bioactive and micronutrient supplementation in depression (Lim et al., 2016).

The present perspective critically discusses the evidence regarding the therapeutic efficacy of vitamin D in depression. A literature search, including publications up until March 2021, was conducted using PubMed and Google Scholar. Search results were screened for relevant articles involving humans and evaluations of vitamin D interventions.

\section{Vitamin D and the brain and the rationale for its use in de- pression}

Vitamin D comprises a group of structurally related, fat-soluble secosteroids. It is produced in the skin during sun exposure and can also be obtained from dietary intake, including vitamin D supplementation (Holick, 2007). The two main forms of vitamin D relevant for humans are vitamin D2 (ergocalciferol) and vitamin D3 (cholecalciferol) (Feldman et al., 2011). Both forms are important for calcium and phosphorus homeostasis (Holick, 2007) and consequently for the maintenance of cellular and neuromuscular function as well as the regulation of bone metabolism (Brown et al., 1999). Vitamin D obtained from dietary sources stems mainly from fungi and yeasts (vitamin D2) or fatty fish (vitamin D3) (Hossein-Nezhad et al., 2013; Jäpelt and Jakobsen, 2013). However, it is difficult to obtain sufficient vitamin D from dietary intake (Maxwell, 1994), and the majority of vitamin D3 is produced in the skin from 7-dehydrocholesterol (provitamin D3) following exposure to ultraviolet B radiation (Holick, 2017). Two hydroxylation steps are needed to form either 1,25-dihydroxyvitamin D2 (ergocalcitriol, 1,25(OH)2D2) or 1,25-dihydroxyvitamin D3 (calcitriol, $1,25(\mathrm{OH}) 2 \mathrm{D} 3)$, which are the active metabolic products of vitamin D2 and D3, respectively (Vieth, 2004). Vitamin D is converted in the liver to 25 -hydroxyvitamin $\mathrm{D}(25(\mathrm{OH}) \mathrm{D})$, the level of which is commonly used to determine a person's vitamin D status (Hollis, 1996), and subsequently in the kidneys to its active form 1,25-dihydroxyvitamin D (1,25(OH)2D) (Wacker and Holick, 2013). Both 1,25(OH)2D2 and 1,25( $\mathrm{OH}) 2 \mathrm{D} 3$ are pleiotropic secosteroid hormones regulating the expression of a large number of genes, responsible for cellular proliferation, differentiation, DNA repair and apoptosis (Hossein-Nezhad et al., 2013), through binding to the vitamin D receptor (Kongsbak et al., 2013; Pike et al., 2010).

Experimental studies have advanced the understanding of the multiple actions of vitamin D in the central nervous system (Kalueff and Tuohimaa, 2007). Vitamin D receptors have been found in brain regions involved in the regulation of behavior, including the cerebral cortex, limbic system and cerebellum, and may also stimulate the release of neurotrophins, which are involved in neuronal development (Kalueff and Tuohimaa, 2007). Vitamin D has been found to play a critical role in brain development (Eyles et al., 2013; Groves et al., 2014; Ko et al., 2004). A deficiency of the vitamin appears to be a risk factor for cognitive decline and dementia in elderly people (Annweiler et al., 2015). Less is known concerning the role of vitamin D in the regulation of affect and mood. Hypovitaminosis $\mathrm{D}$ has been hypothesized to induce negative mood and depression (Berk et al., 2007). Since vitamin D receptors are present on neurons and glial cells in brain areas thought to be involved in the pathophysiology of depression, e.g. cingulate cortex and hippocampus (Eyles et al., 2005), and an interaction between vitamin D and glucocorticoids has been found in the hippocampus (Obradovic et al., 2006), the potential role of vitamin D as a therapeutic agent in depression has been investigated. Vitamin D appears to be involved in the control of serotonin formation, implying a link between vitamin D deficiency and depression (Patrick and Ames, 2015). Vitamin D has been theorized to act as a neuroactive hormone (Berridge, 2015a; Berridge, 2015b; Berridge, 2017). Furthermore, vitamin $D$ has been postulated to modulate neuronal calcium ion levels and thereby to cause the onset of depressive symptoms, with vitamin D deficiency leading to elevated neuronal $\mathrm{Ca}^{2+}$ and increasing depression (Berridge, 2017). In addition, vitamin D may be involved in neuro-immunomodulation and neuroplasticity, both of which have been proposed as mechanisms underlying its effects on mood (Fernandes de Abreu et al., 2009).

Vitamin D deficiency (defined as serum 25(OH)D concentration of less than $50 \mathrm{nmol} / \mathrm{L}$ ) or insufficiency are common in people of all age groups, with approximately one billion individuals affected worldwide (Holick, 2007). Several observational studies, including case-control studies, cross-sectional studies and cohort studies, have investigated the relationship between vitamin D and depression. Various epidemiological studies have shown associations between serum $25(\mathrm{OH}) \mathrm{D}$ levels and depression, with vitamin D deficiency being associated with depression (Black et al., 2014; Brouwer-Brolsma et al., 2015; Ganji et al., 2010; Hoang et al., 2011; Hoogendijk et al., 2008; Jamilian et al., 2013; Kerr et al., 2015; Kjærgaard et al., 2011; Lee et al., 2011; Milaneschi et al., 2010; Parker et al., 2017; Tolppanen et al., 2012; von Känel et al., 2015). However, other studies have found no association (e.g. Nanri et al., 2009; Pan et al., 2009; Zhao et al., 2010).

A systematic review and meta-analysis summarizing the available evidence from cross-sectional and prospective cohort studies reported a pooled estimate of the adjusted odds ratio of depression in 11 cross-sectional studies (with a total of 43,137 participants) of $0.96\left(95 \% \mathrm{CI}=0.94-0.99, \mathrm{I}^{2}=63 \%\right)$ for a $10 \mathrm{ng} / \mathrm{ml}$ increase in 25(OH)D level (Ju et al., 2013). For five cohort studies comprising 12,648 primarily elderly participants, with 2,663 experiencing depression events during follow-up, the pooled adjusted odds ratio of depression was $0.92\left(95 \% \mathrm{CI}=0.87-0.98, \mathrm{I}^{2}=50 \%\right)$ for a 10 $\mathrm{ng} / \mathrm{ml}$ increase in $25(\mathrm{OH}) \mathrm{D}$ levels (Ju et al., 2013). A further systematic review and meta-analysis pooling the results of previous epidemiological studies reported a positive association between hypovitaminosis $\mathrm{D}$ and depression in adults (odds ratio $=1.31$; 95\% CI, 1.00-1.71) (Anglin et al., 2013). The link between vitamin $\mathrm{D}$ concentrations and depression has been suggested to be less straightforward than commonly assumed. The association may 
Table 1. Observational evidence of a relationship between vitamin D and depression

Associations between hypovitaminosis D and depression in adults (Anglin et al., 2013; Ju et al., 2013)

Reduced risk of developing depression in people with higher serum 25(OH)D levels (Jääskeläinen et al., 2015)

Association of depression with vitamin D deficiency in older adults (Okereke and Singh, 2016)

Association of low baseline levels of 25(OH)D3 with increased depression scores at 3-year and 6-year follow-up in elderly adults (Milaneschi et al., 2010)

Association of depression with vitamin D deficiency in young people (Kerr et al., 2015; Polak et al., 2014)

Association of depression with vitamin D deficiency in individuals with heart failure and cancer (Björkhem-Bergman and Bergman, 2016; Johansson et al., 2016)

Association between vitamin D status and antenatal and postpartum depression (Aghajafari et al., 2018)

Caveat: Correlation between low vitamin D levels and depressive symptoms is not necessarily indicative of a causal role of hypovitaminosis $\mathrm{D}$ in depression due to potential confounders (age, dietary intake, physical exercise, time spent outdoors etc.)

have been overestimated, particularly in older people, since both hypovitaminosis $\mathrm{D}$ and depression are highly prevalent in this age group (Rastmanesh et al., 2012) (see also Table 1).

Vitamin D has also been implicated in antenatal depression and postpartum depression. However, this association is complex and the available findings are inconsistent. In a systematic review, a significant association between vitamin $\mathrm{D}$ status and both antenatal and postpartum depression was reported (Aghajafari et al., 2018). The findings of a meta-analysis of nine longitudinal studies suggested that vitamin D deficiency could be a modifiable risk factor of postpartum depression but not of depressive symptoms during pregnancy (Wang et al., 2018).

The correlation between low vitamin D levels and depressive symptoms does not necessarily indicate that hypovitaminosis D plays a causal role in depression, since a wide range of potential confounders, such as age, dietary intake, physical exercise, time spent outdoors, as well as alcohol and tobacco may play a role (Bertone-Johnson, 2009). It is conceivable that low vitamin D levels result from depression, since depressed mood and apathy may lead to a decrease in exposure to sunlight or intake of food rich in vitamin D (Rastmanesh et al., 2012). A decrease in vitamin D concentrations may therefore be an antecedent or a consequence of depression, and causality should be examined in prospective studies assessing mood changes over time. A six-year prospective study comprising 954 elderly individuals aged 65 years or older investigated the association of baseline vitamin D levels and subsequent occurrence of depression (Milaneschi et al., 2010). In this study, people with low baseline concentrations of $25(\mathrm{OH}) \mathrm{D} 3(<50 \mathrm{nM}$ or $<20 \mathrm{ng} / \mathrm{ml}$ ) were reported to show significantly increased depression scores at three-year and six-year follow-up in comparison with those with high baseline levels (Milaneschi et al., 2010). However, this difference may also be explained by different lifestyles.

\section{Intervention studies using vitamin $D$ in depression}

Intervention studies administering vitamin D have been conducted in people with major depression and seasonal affective disorder as well as women with postpartum depression and elderly individuals with depressive symptoms (see Table 2). A systematic review of six randomized controlled trials (with 1,203 participants including 71 depressed individuals) investigated the efficacy of oral vitamin $\mathrm{D}$ administration versus placebo in adults at risk of depression, with symptoms of depression or with a primary diagnosis of depression (Li et al., 2014). No significant effects of vitamin D supplementation on depression scores or in subgroup or sensitivity analyses were found; the quality of evidence was considered low (Li et al., 2014). A further systematic review and meta-analysis of randomized controlled trials summarized the effects of vitamin D supplementation on depressive symptoms or depression (Shaffer et al., 2014). No overall effects of vitamin D supplementation

Table 2. Interventional evidence of a relationship between vitamin $\mathrm{D}$ and depression

No significant meta-analytical effect on depression following vitamin D supplementation (Li et al., 2014; Lázaro Tomé et al., 2021)

No overall meta-analytical effect of vitamin D supplementation on depressive symptoms, but moderate, statistically significant effect in people with clinically significant depressive symptoms or depressive disorder (Shaffer et al., 2014)

No significant improvement of depression following vitamin D supplementation in a meta-analysis of studies with individuals with low depression levels and sufficient vitamin D levels at baseline (Gowda et al., 2015)

Significant worsening of depression following vitamin D supplementation in a meta-analysis of "biologically flawed" studies (e.g. vitamin $D$ deficiency not established at baseline and/or vitamin D dose administered insufficient to produce normal vitamin D levels) (Spedding, 2014)

Significant improvement of depression following vitamin D supplementation in a meta-analysis of studies without biological flaws (Spedding, 2014)

Favorable findings following vitamin D supplementation ( $\geq 800$ I.U. daily) in studies demonstrating a change in vitamin levels (Spedding, 2014)

Dose dependency of effects of importance of vitamin D supplementation (Mozaffari-Khosravi et al., 2013)

Summary: Insufficient evidence in support of therapeutic efficacy of vitamin D supplementation in depression 
Table 3. Problems and future directions regarding vitamin D and depression

Unclear causality of correlations between vitamin D status and depressive symptoms

Intervention trials needed in people who are both depressed and deficient in vitamin D

Assessment of depression level and vitamin D status both at trial baseline and follow-up

Investigations needed regarding vitamin D effects in different types of depressive disorders (major depressive disorder, seasonal affective disorder, bipolar disorder, antenatal and postpartum depression, premenstrual dysphoric disorder)

Optimal dosage, duration and mode of delivery of vitamin D supplementation

Summary: Large-scale, randomized controlled trials of vitamin D in people with well-defined diagnoses of depression needed

on depressive symptoms were found. However, subgroup analysis showed that vitamin D supplementation had a moderate, statistically significant effect in individuals with clinically significant depressive symptoms or depressive disorder and a small, non-significant effect in those without clinically significant depression. The trials included in this review varied in respect of dose, frequency, duration and mode of delivery of vitamin D administration (Shaffer et al., 2014). A meta-analysis of nine randomized controlled trials (with a total of 4,923 participants) estimated the weighted mean effect of vitamin D supplementation in decreasing depressive symptoms in adult participants diagnosed with depression or depressive symptoms (Gowda et al., 2015). No significant reduction in depression was observed following vitamin D supplementation. However, most of the studies had included people with low depression levels and sufficient concentrations of serum vitamin D at baseline. The vitamin $\mathrm{D}$ doses used and intervention durations varied between the studies included in the meta-analytical review (Gowda et al., 2015). A recent systematic review and meta-analysis including 10 randomized controlled trials (with a total of 1,393 participants) found no significant effect of oral vitamin D administration on post-intervention depression scores (Lázaro Tomé et al., 2021). The vitamin D dose administered appears to be important. In a randomized controlled trial conducted in depressed people with initial hypovitaminosis $\mathrm{D}$, a single intramuscular injection of 300,000 I.U. of vitamin D improved symptoms of depression three months following intervention more than a dose of 150,000 I.U. (Mozaffari-Khosravi et al., 2013).

"Biological flaws" in primary studies have been suggested to be a reason why meta-analyses have failed to show efficacy of vitamin D supplementation in depression (Lappe and Heaney, 2012). The concept of biological flaws refers to limitations in study design, which may affect a study's ability to test the research hypothesis. For example, the hypothesis that the treatment of a vitamin D deficit improves depressive symptoms can be tested only if vitamin D deficiency is established at baseline and the vitamin D dose administered is capable of producing sufficient levels of vitamin D during the trial (Heaney, 2012). Therefore, meta-analytical studies have been conducted according to the presence or absence of biological flaws (Spedding, 2014). While a meta-analysis of the available studies without flaws showed a statistically significant improvement in depression following vitamin D supplementation, the results of studies with biological flaws were mainly inconclusive, with the metaanalysis performed showing a statistically significant worsening in depression following vitamin D administration (Spedding, 2014). Vitamin D supplementation of $\geq 800$ I.U. daily demonstrated favorable results in the therapy of depression in the studies with a change in vitamin levels, with the effect size being comparable to that of antidepressant medication (Spedding, 2014).

A recent 28-day trial investigating vitamin D3 supplementation in addition to usual treatment in children and adolescents with vitamin $\mathrm{D}$ deficiency $(25(\mathrm{OH}) \mathrm{D} \leq 30 \mathrm{nmol} / \mathrm{l})$ and at least mild de- pression (according to Beck Depression Inventory) failed to show a vitamin D effect on self-rated depression (Libuda et al., 2020).

In summary, the current evidence is insufficient to support the efficacy of vitamin D supplementation in the treatment of depression. Further large-scale randomized controlled trials assessing the efficacy of vitamin D supplementation are required. In particular, future trials should be conducted in people who are both depressed and deficient in vitamin $\mathrm{D}$, with the vitamin $\mathrm{D}$ doses supplemented being large enough to achieve sufficient vitamin levels.

\section{Future directions}

The role of vitamin D in the etiology and treatment of depression is still unclear (see Table 3). Due to various methodological problems and questionable scientific rigor of the available studies, there is no unequivocal evidence of an association between vitamin D status and depressive symptoms or the diagnosis of depression. In particular, the relationship reported in several studies between hypovitaminosis D and mood could have been influenced by confounding variables. The association between vitamin $\mathrm{D}$ and depression may be indirectly explained by other factors affecting both vitamin status and mood. For example, exposure to sunlight influences not only vitamin D synthesis in the skin but also body circadian rhythms (e.g. melatonin), which have been shown to be involved in depression (Boyce and Barriball, 2010). Another covariable possibly playing a role is body mass index, with fat-soluble vitamin $\mathrm{D}$ being sequestered in adipose tissue and hypovitaminosis $\mathrm{D}$ arising from both high body mass index and depression (Forsythe et al., 2012). Furthermore, physical exercise levels may affect both vitamin D status and mood, since reduced physical activity has been observed in both individuals with depression and people with low levels of vitamin D (Annweiler et al., 2011). Recent investigations have attempted to take relevant covariables into account, with prospective longitudinal studies reporting an elevated hazard ratio for depression in people with hypovitaminosis D at baseline (see Anglin et al., 2013). While this suggests that hypovitaminosis D precedes the onset of depression, observational studies are unable to establish causality. In addition, the link between vitamin $\mathrm{D}$ and depression could be related to genetic predisposition, since gene locus $11 \mathrm{p} 15$ harbors susceptibility genes for mood disorders (Huang et al., 2010) and is also involved in vitamin D metabolism (Wang et al., 2010). Experimental and randomized controlled intervention trials are required to shed further light on the link between vitamin D status and depression.

Major problems of the available treatment studies examining the efficacy of vitamin $\mathrm{D}$ in depression include non-representative samples, problems with the generalization of findings, heterogeneity of the trial participants regarding the severity of depressive symptoms, the methods used to assess depression, the presence of 
comorbidities, the dose and duration of supplementation and the levels of 25(OH)D at baseline and follow-up. Polymorphisms of the vitamin D receptor gene modulate the effectiveness of vitamin $\mathrm{D}$ in the central nervous system, and this may explain why some individuals with depression respond to vitamin D and others do not (Kuningas et al., 2009).

Future intervention studies need to distinguish between different types of depressive disorders, such as major depressive disorder, seasonal affective disorder, bipolar disorder, postpartum depression and premenstrual dysphoric disorder. Intervention trials with biological flaws may demonstrate the methodological limitations of the study design rather than the efficacy of vitamin D supplementation. Therefore, future studies need to include individuals who are both depressed and vitamin D deficient and should examine depression level and vitamin D status both at baseline and follow-up. Studies employing sufficient doses of vitamin D and intervention periods capable of significantly increasing vitamin D levels in well-defined, homogenous risk groups are warranted.

Given a variety of adverse effects of hypovitaminosis D and the general health benefits and low risk of serious adverse effects of vitamin D supplements (Annweiler et al., 2011; Jorde et al., 2013), vitamin D supplementation may be recommended to protect against depression. In particular, sensible and moderate sun exposure, avoiding even mild sunburn (Kennedy et al., 2003), of arms, legs, abdomen and back can help supplement vitamin D and induce the production of beta-endorphin in the skin, which may also improve wellbeing (Zanello et al., 1999). The combination of sunlight exposure and physical exercise may be particularly beneficial (Lange, 2018). Since the synthesis of vitamin D in the skin following sunlight exposure is strongly influenced by various factors, such as age, skin pigmentation, season and latitude, dietary supplementation may be needed to obtain beneficial effects. For the treatment of vitamin deficiency, the administration of 50,000 I.U. of vitamins D2 or D3 once a week for 8 weeks has been recommended in order to raise blood concentrations of $25(\mathrm{OH}) \mathrm{D}$ to an adequate range of at least $30 \mathrm{ng} / \mathrm{ml}$ or preferably $40-60 \mathrm{ng} / \mathrm{ml}$, while a dose of 50,000 I.U. vitamin D2 or vitamin D3 once every other week has been suggested to be effective in maintaining vitamin D sufficiency (Holick et al., 2011).

\section{Conclusion}

Despite the available findings suggesting that hypovitaminosis $\mathrm{D}$ elevates the risk of depressive mood, the evidence of observational and interventional studies is insufficient to establish causality between low vitamin D levels and the occurrence of depression. Whether or not vitamin D sufficiency has protective efficacy against incident depression or recurrence requires future investigation. Further well-designed, large-scale, long-term intervention trials of vitamin D supplementation in people of different age groups with depressive symptoms, diagnosed depression, postpartum depression or other depressive disorders would be of value in examining the therapeutic efficacy of vitamin D. Given the general health benefits and low risk of adverse effects of vitamin $\mathrm{D}$, modest sun exposure and dietary vitamin $\mathrm{D}$ enrichment may be recommended in order to supplement vitamin D and improve mood and wellbeing. However, this recommendation requires confirmation by future studies.

\section{References}

Aghajafari, F., Letourneau, N., Mahinpey, N., Cosic, N., and Giesbrecht, G.
(2018). Vitamin D deficiency and antenatal and postpartum depression: a systematic review. Nutrients. 10: 478.

American Psychiatric Association. (2013). Diagnostic and Statistical Manual of Mental Disorders, 5th ed. American Psychiatric Association, Washington, DC.

Anderson, H.D., Pace, W.D., Libby, A.M., West, D.R., and Valuck, R.J. (2012). Rates of 5 common antidepressant side effects among new adult and adolescent cases of depression: a retrospective US claims study. Clin. Ther. 34: 113-123.

Anglin, R.E.S., Samaan, Z., Walter, S.D., and McDonald, S.D. (2013). Vitamin $D$ deficiency and depression in adults: Systematic review and meta-analysis. Br. J. Psychiatry. 202: 100-107.

Annweiler, C., Dursun, E., Féron, F., Gezen-Ak, D., Kalueff, A.V., Littlejohns, T., Llewellyn, D.J., Millet, P., Scott, T., Tucker, K.L., Yilmazer, S., and Beauchet, O. (2015). 'Vitamin D and cognition in older adults': updated international recommendations. J. Intern. Med. 277: 45-57.

Annweiler, C., Souberbielle, J.-C., Schott, A.-M., de Decker, L., Berrut, G., and Beauchet, O. (2011). Vitamine D chez la personne âgée les 5 points à retenir. Geriatr. Psychol. Neuropsychiatr. Vieil. 9: 259-267.

Bennett, B.J., Hall, K.D., Hu, F.B., McCartney, A.L., and Roberto, C. (2015). Nutrition and the science of disease prevention: a systems approach to support metabolic health. Ann. N. Y. Acad. Sci. 1352: 1-12.

Berk, M., Sanders, K.M., Pasco, J.A., Jacka, F.N., Williams, L.J., Hayles, A.L., and Dodd, S. (2007). Vitamin D deficiency may play a role in depression. Med. Hypotheses. 69: 1316-1319.

Berridge, M.J. (2015a). Vitamin D cell signalling in health and disease. Biochem. Biophys. Res. Commun. 460: 53-71.

Berridge, M.J. (2015b). Vitamin D: a custodian of cell signalling stability in health and disease. Biochem. Soc. Trans. 43: 349-358.

Berridge, M.J. (2017). Vitamin D and depression: cellular and regulatory mechanisms. Pharmacol. Rev. 69: 80-92.

Bertone-Johnson, E.R. (2009). Vitamin D and the occurrence of depression: causal association or circumstantial evidence? Nutr. Rev. 67: 481-492.

Björkhem-Bergman, L., and Bergman, P. (2016). Vitamin D and patients with palliative cancer. BMJ Support. Palliat. Care. 6: 287-291.

Black, L.J., Jacoby, P., Allen, K.L., Trapp, G.S., Hart, P.H., Byrne, S.M., Mori, T.A., Beilin, L.J., and Oddy, W.H. (2014). Low vitamin D levels are associated with symptoms of depression in young adult males. Aust. N. Z. J. Psychiatry. 48: 464-471.

Boyce, P., and Barriball, E. (2010). Circadian rhythms and depression. Aust. Fam. Physician. 39: 307-310.

Broadhead, W.E., Blazer, D.G., George, L.K., and Tse, C.K. (1990). Depression, disability days, and days lost from work in a prospective epidemiologic survey. JAMA 264: 2524-2528.

Bromet, E., Andrade, L.H., Hwang, I., Sampson, N.A., Alonso, J., de Girolamo, G., de Graaf, R., Demyttenaere, K., Hu, C., Iwata, N., Karam, A.N., Kaur, J., Kostyuchenko, S., Lépine, J.P., Levinson, D., Matschinger, H., Mora, M.E., Browne, M.O., Posada-Villa, J., Viana, M.C., Williams, D.R., and Kessler, R.C. (2011). Cross-national epidemiology of DSM-IV major depressive episode. BMC Med. 9: 90.

Brouwer-Brolsma, E.M., Dhonukshe-Rutten, R.A.M., van Wijngaarden, J.P., van der Zwaluw, N.L., Sohl, E., In't Veld, P.H., van Dijk, S.C., Swart, K.M.A., Enneman, A.W., Ham, A.C., van Schoor, N.M., van der Velde, N., Uitterlinden, A.G., Lips, P., Feskens, E.J.M., and de Groot, L.C.P.G.M. (2015). Low vitamin D status is associated with more depressive symptoms in Dutch older adults. Eur. J. Nutr. 55(4): 15251534.

Brown, A.J., Dusso, A., and Slatopolsky, E. (1999). Vitamin D. Am. J. Physiol. 277: F157-F175.

Bschor, T., and Baethge, C. (2010). No evidence for switching the antidepressant: systematic review and meta-analysis of RCTs of a common therapeutic strategy. Acta Psychiatr. Scand. 121: 174-179.

Casacalenda, N., Perry, J.C., and Looper, K. (2002). Remission in major depressive disorder: a comparison of pharmacotherapy, psychotherapy, and control conditions. Am. J. Psychiatry. 159: 1354-1360.

Cuijpers, P., Dekker, J., Hollon, S.D., and Andersson, G. (2009). Adding psychotherapy to pharmacotherapy in the treatment of depressive disorders in adults: a meta-analysis. J. Clin. Psychiatry. 70: 1219-1229.

Cuijpers, P., van Straten, A., van Oppen, P., and Andersson, G. (2008). Are psychological and pharmacologic interventions equally effective in 
the treatment of adult depressive disorders? A meta-analysis of comparative studies. J. Clin. Psychiatry. 69: 1675-85.

Eyles, D.W., Burne, T.H.J., and McGrath, J.J. (2013). Vitamin D, effects on brain development, adult brain function and the links between low levels of vitamin $D$ and neuropsychiatric disease. Front. Neuroendocrinol. 34: 47-64.

Eyles, D.W., Smith, S., Kinobe, R., Hewison, M., and McGrath, J.J. (2005). Distribution of the vitamin $D$ receptor and 1 alpha-hydroxylase in human brain. J. Chem. Neuroanat. 29: 21-30.

Fava, M. (2003). Diagnosis and definition of treatment-resistant depression. Biol. Psychiatry. 53: 649-659.

Feldman, D., Pike, J.W., and Adams, J.S. (Ed.). (2011). In: Vitamin D. 3rd ed. Elsevier, New York.

Fernandes de Abreu, D.A., Eyles, D., and Féron, F. (2009). Vitamin D, a neuro-immunomodulator: implications for neurodegenerative and autoimmune diseases. Psychoneuroendocrinology. 34(Suppl 1): S265-S277.

Forsythe, L.K., Livingstone, M.B.E., Barnes, M.S., Horigan, G., McSorley, E.M., Bonham, M.P., Magee, P.J., Hill, T.R., Lucey, A.J., Cashman, K.D., Kiely, M., Strain, J.J., and Wallace, J.M.W. (2012). Effect of adiposity on vitamin $\mathrm{D}$ status and the 25 -hydroxycholecalciferol response to supplementation in healthy young and older Irish adults. Br. J. Nutr. 107: 126-134.

Ganji, V., Milone, C., Cody, M.M., McCarty, F., and Wang, Y.T. (2010). Serum vitamin $D$ concentrations are related to depression in young adult US population: the Third National Health and Nutrition Examination Survey. Int. Arch. Med. 3: 29.

Goethe, J.W., Woolley, S.B., Cardoni, A.A., Woznicki, B.A., and Piez, D.A. (2007). Selective serotonin reuptake inhibitor discontinuation: side effects and other factors that influence medication adherence. J. Clin. Psychopharmacol. 27: 451-458.

Gowda, U., Mutowo, M.P., Smith, B.J., Wluka, A.E., and Renzaho, A.M.N. (2015). Vitamin D supplementation to reduce depression in adults: meta-analysis of randomized controlled trials. Nutrition. 31: 421429.

Groves, N.J., McGrath, J.J., and Burne, T.H.J. (2014). Vitamin D as a neurosteroid affecting the developing and adult brain. Annu. Rev. Nutr. 34: 117-141.

Heaney, R.P. (2012). Vitamin D--baseline status and effective dose. N. Engl. J. Med. 367: 77-78.

Hoang, M.T., Defina, L.F., Willis, B.L., Leonard, D.S., Weiner, M.F., and Brown, E.S. (2011). Association between low serum 25-hydroxyvitamin $D$ and depression in a large sample of healthy adults: the Cooper Center longitudinal study. Mayo Clin. Proc. 86: 1050-1055.

Holick, M.F. (2007). Vitamin D deficiency. N. Engl. J. Med. 357: 266-281.

Holick, M.F. (2017). Ultraviolet B radiation: the vitamin D connection. Adv. Exp. Med. Biol. 996: 137-154.

Holick, M.F., Binkley, N.C., Bischoff-Ferrari, H.A., Gordon, C.M., Hanley, D.A., Heaney, R.P., Murad, M.H., and Weaver, C.M. (2011). Evaluation, treatment, and prevention of vitamin D deficiency: an Endocrine Society clinical practice guideline. J. Clin. Endocrinol. Metab. 96: 1911-1930.

Hollis, B.W. (1996). Assessment of vitamin D nutritional and hormonal status: what to measure and how to do it. Calcif. Tissue Int. 58: 4-5.

Hoogendijk, W.J.G., Lips, P., Dik, M.G., Deeg, D.J.H., Beekman, A.T.F., and Penninx, B.W.J.H. (2008). Depression is associated with decreased 25-hydroxyvitamin $D$ and increased parathyroid hormone levels in older adults. Arch. Gen. Psychiatry. 65: 508-512.

Hossein-Nezhad, A., and Holick, M.F. (2013). Vitamin D for health: a global perspective. Mayo Clin. Proc. 88: 720-755.

Hossein-Nezhad, A., Spira, A., and Holick, M.F. (2013). Influence of vitamin D status and vitamin D3 supplementation on genome wide expression of white blood cells: a randomized double-blind clinical trial. PLoS One 8: e58725.

Huang, J., Perlis, R.H., Lee, P.H., Rush, A.J., Fava, M., Sachs, G.S., Lieberman, J., Hamilton, S.P., Sullivan, P., Sklar, P., Purcell, S., and Smoller, J.W. (2010). Cross-disorder genomewide analysis of schizophrenia, bipolar disorder, and depression. Am. J. Psychiatry. 167: 1254-1263.

Insel, T.R. (2015). The NIMH experimental medicine initiative. World Psychiatry. 14(2): 151-153.

Jääskeläinen, T., Knekt, P., Suvisaari, J., Männistö, S., Partonen, T., Sääk- sjärvi, K., Kaartinen, N.E., Kanerva, N., and Lindfors, O. (2015). Higher serum 25-hydroxyvitamin $D$ concentrations are related to a reduced risk of depression. Br. J. Nutr. 113: 1418-1426.

Jamilian, H., Bagherzadeh, K., Nazeri, Z., and Hassanijirdehi, M. (2013). Vitamin $D$, parathyroid hormone, serum calcium and phosphorus in patients with schizophrenia and major depression. Int. J. Psychiatry Clin. Pract. 17: 30-34.

Jäpelt, R.B., and Jakobsen, J. (2013). Vitamin D in plants: a review of occurrence, analysis, and biosynthesis. Front. Plant Sci. 4: 136.

Johansson, P., Alehagen, U., van der Wal, M.H., Svensson, E., and Jaarsma, T. (2016). Vitamin D levels and depressive symptoms in patients with chronic heart failure. Int. J. Cardiol. 207: 185-189.

Jorde, R., Strand Hutchinson, M., Kjærgaard, M., Sneve, M., and Grimnes, G. (2013). Supplementation with high doses of vitamin D to subjects without vitamin $D$ deficiency may have negative effects: pooled data from four intervention trials in Troms $\varnothing$. ISRN Endocrinology. 2013: 348705.

Jorm, A.F. (2000). Mental health literacy. Public knowledge and beliefs about mental disorders. Br. J. Psychiatry. 177: 396-401.

Ju, S.-Y., Lee, Y.-J., and Jeong, S.-N. (2013). Serum 25-hydroxyvitamin D levels and the risk of depression: a systematic review and meta-analysis. J. Nutr. Health Aging. 17: 447-455.

Kalueff, A.V., and Tuohimaa, P. (2007). Neurosteroid hormone vitamin D and its utility in clinical nutrition. Curr. Opin. Clin. Nutr. Metab. Care. 10: 12-19.

von Känel, R., Fardad, N., Steurer, N., Horak, N., Hindermann, E., Fischer, F., and Gessler, K. (2015). Vitamin D deficiency and depressive symptomatology in psychiatric patients hospitalized with a current depressive episode: a factor analytic study. PLoS One 10: e0138550.

Kennedy, C., Bajdik, C.D., Willemze, R., De Gruijl, F.R., and Bouwes Bavinck, J.N. (2003). The influence of painful sunburns and lifetime sun exposure on the risk of actinic keratoses, seborrheic warts, melanocytic nevi, atypical nevi, and skin cancer. J. Invest. Dermatol. 120: 1087-1093.

Kerr, D.C.R., Zava, D.T., Piper, W.T., Saturn, S.R., Frei, B., and Gombart, A.F. (2015). Associations between vitamin D levels and depressive symptoms in healthy young adult women. Psychiatry Res. 227: 46-51.

Kessler, R.C., and Bromet, E.J. (2013). The epidemiology of depression across cultures. Annu. Rev. Publ. Health 34: 119-138.

Kessler, R.C., Angermeyer, M., Anthony, J.C., de Graaf, R., Demyttenaere, K., Gasquet, I., de Girolamo, G., Gluzman, S., Gureje, O., Haro, J.M., Kawakami, N., Karam, A., Levinson, D., Medina Mora, M.E., Oakley Browne, M.A., Posada-Villa, J., Stein, D.J., Adley Tsang, C.H., AguilarGaxiola, S., Alonso, J., Lee, S., Heeringa, S., Pennell, B.-E., Berglund, P., Gruber, M.J., Petukhova, M., Chatterji, S., and Ustün, T.B. (2007). Lifetime prevalence and age-of-onset distributions of mental disorders in the World Health Organization's World Mental Health Survey Initiative. World Psychiatry. 6: 168-176.

Kessler, R.C., Berglund, P., Demler, O., Jin, R., Koretz, D., Merikangas, K.R., Rush, A.J., Walters, E.E., and Wang, P.S. (2003). The epidemiology of major depressive disorder: results from the National Comorbidity Survey Replication (NCS-R). JAMA 289: 3095-3105.

Kjærgaard, M., Joakimsen, R., and Jorde, R. (2011). Low serum 25-hydroxyvitamin $D$ levels are associated with depression in an adult Norwegian population. Psychiatry Res. 190: 221-225.

Ko, P., Burkert, R., McGrath, J., and Eyles, D. (2004). Maternal vitamin D3 deprivation and the regulation of apoptosis and cell cycle during rat brain development. Brain Res. Dev. Brain Res. 153: 61-68.

Kongsbak, M., Levring, T.B., Geisler, C., and von Essen, M.R. (2013). The vitamin d receptor and T cell function. Front. Immunol. 4: 148 .

Krishnan, V., and Nestler, E.J. (2010). Linking molecules to mood: new insight into the biology of depression. Am. J. Psychiatry. 167: 13051320

Kuningas, M., Mooijaart, S.P., Jolles, J., Slagboom, P.E., Westendorp, R.G.J., and van Heemst, D. (2009). VDR gene variants associate with cognitive function and depressive symptoms in old age. Neurobiol. Aging. 30: 466-473.

Lai, J.S., Hiles, S., Bisquera, A., Hure, A.J., McEvoy, M., and Attia, J. (2014). A systematic review and meta-analysis of dietary patterns and depression in community-dwelling adults. Am. J. Clin. Nutr. 99: 181-197.

Lange, K.W. (2018). Diet, exercise, and mental disorders - public health 
challenges of the future. Mov. Nutr. Health Dis. 2: 39-59.

Lange, K.W. (2020a). Lipids in the treatment of mental disorders. In: Shahidi, F. (Ed.). Bailey's Industrial Oil and Fat Products. Wiley, pp. 371-390.

Lange, K.W. (2020b). Omega-3 fatty acids and mental health. Glob. Health J. $4: 18-30$.

Lange, K.W. (2021). Lack of evidence for efficacy of omega-3 fatty acids in depression. Acta Psychiatr. Scand. 144: 415-416.

Lange, K.W., Nakamura, Y., and Lange, K.M. (2020). The use of probiotics in depression. J. Food Bioact. 12: 3-8.

Lange, K.W., Nakamura, Y., Zhao, H., Bai, D., and Wang, H. (2021a). Are omega-3 fatty acids efficacious in the treatment of depression? A review. J. Food Bioact. 14: 10-19.

Lange, K.W., Nakamura, Y., Lange, K.M., and Zhao, H. (2021b). Tea and depression. Food Sci. Hum. Wellness in press.

Lappe, J.M., and Heaney, R.P. (2012). Why randomized controlled trials of calcium and vitamin D sometimes fail. Dermatoendocrinol. 4 95-100.

Lee, D.M., Tajar, A., O'Neill, T.W., O'Connor, D.B., Bartfai, G., Boonen, S. Bouillon, R., Casanueva, F.F., Finn, J.D., Forti, G., Giwercman, A., Han, T.S., Huhtaniemi, I.T., Kula, K., Lean, M.E., Punab, M., Silman, A.J., Vanderschueren, D., Wu, F.C., and Pendleton, N. (2011). Lower vitamin D levels are associated with depression among communitydwelling European men. J. Psychopharmacol. 25: 1320-1328.

Li, G., Mbuagbaw, L., Samaan, Z., Falavigna, M., Zhang, S., Adachi, J.D., Cheng, J., Papaioannou, A., and Thabane, L. (2014). Efficacy of vitamin $D$ supplementation in depression in adults: a systematic review. J. Clin. Endocrinol. Metab. 99: 757-767.

Libuda, L., Timmesfeld, N., Antel, J., Hirtz, R., Bauer, J., Führer, D., Zwanziger, D., Öztürk, D., Langenbach, G., Hahn, D., Ring, S., Peters, T., Hinney, A., Bühlmeier, J., Hebebrand, J., Grasemann, C., and Föcker, M. (2020). Effect of vitamin D deficiency on depressive symptoms in child and adolescent psychiatric patients: results of a randomized controlled trial. Eur. J. Nutr. 59: 3415-3424.

Lim, S.Y., Kim, E.J., Kim, A., Lee, H.J., Choi, H.J., and Yang, S.J. (2016). Nutritional factors affecting mental health. Clin. Nutr. Res. 5(3): 143-152.

Malhi, G.S., and Mann, J.J. (2018). Depression. Lancet. 392(10161): 22992312.

Marx, W., Moseley, G., Berk, M., and Jacka, F. (2017). Nutritional psychiatry: the present state of the evidence. Proc. Nutr. Soc. 76: 427-436

Maxwell, J.D. (1994). Seasonal variation in vitamin D. Proc. Nutr. Soc. 53 : 533-543.

Milaneschi, Y., Shardell, M., Corsi, A.M., Vazzana, R., Bandinelli, S., Guralnik, J.M., and Ferrucci, L. (2010). Serum 25-hydroxyvitamin D and depressive symptoms in older women and men. J. Clin. Endocrinol. Metab. 95: 3225-3233.

Miller, G. (2010). Is pharma running out of brainy ideas? Science 329(5991): 502-504.

Mozaffari-Khosravi, H., Nabizade, L., Yassini-Ardakani, S.M., Hadinedoushan, H., and Barzegar, K. (2013). The effect of 2 different single injections of high dose of vitamin $D$ on improving the depression in depressed patients with vitamin D deficiency: a randomized clinical trial. J. Clin. Psychopharmacol. 33: 378-385.

Nanri, A., Mizoue, T., Matsushita, Y., Poudel-Tandukar, K., Sato, M., Ohta, M., and Mishima, N. (2009). Association between serum 25-hydroxyvitamin $\mathrm{D}$ and depressive symptoms in Japanese: analysis by survey season. Eur. J. Clin. Nutr. 63: 1444-1447.

Obradovic, D., Gronemeyer, H., Lutz, B., and Rein, T. (2006). Cross-talk of vitamin $D$ and glucocorticoids in hippocampal cells. J. Neurochem. 96: 500-509.

Okereke, O.I., and Singh, A. (2016). The role of vitamin D in the prevention of late-life depression. J. Affect. Disord. 198: 1-14.

Opie, R.S., O'Neil, A., Itsiopoulos, C., and Jacka, F.N. (2015). The impact of whole-of-diet interventions on depression and anxiety: a systematic review of randomised controlled trials. Public Health Nutr. 18 2074-2093.

Parker, G.B., Brotchie, H., and Graham, R.K. (2017). Vitamin D and depression. J. Affect. Disord. 208: 56-61.

Polak, M.A., Houghton, L.A., Reeder, A.I., Harper, M.J., and Conner, T.S (2014). Serum 25-hydroxyvitamin D concentrations and depressive symptoms among young adult men and women. Nutrients 6: 4720-
4730

Pan, A., Lu, L., Franco, O.H., Yu, Z., Li, H., and Lin, X. (2009). Association between depressive symptoms and 25-hydroxyvitamin D in middleaged and elderly Chinese. J. Affect. Disord. 118: 240-243.

Patrick, R.P., and Ames, B.N. (2015). Vitamin D and the omega-3 fatty acids control serotonin synthesis and action, part 2: relevance for ADHD, bipolar disorder, schizophrenia, and impulsive behavior. FASEB J. 29: 2207-2222.

Pietrzak, R.H., Kinley, J., Afifi, T.O., Enns, M.W., Fawcett, J., and Sareen, J. (2013). Subsyndromal depression in the United States: prevalence, course, and risk for incident psychiatric outcomes. Psychol. Med. 43 1401-1414.

Pike, J.W., Meyer, M.B., Martowicz, M.L., Bishop, K.A., Lee, S.M., Nerenz, R.D., and Goetsch, P.D. (2010). Emerging regulatory paradigms for control of gene expression by 1,25-dihydroxyvitamin D3. J. Steroid Biochem. Mol. Biol. 121: 130-135.

Psaltopoulou, T., Sergentanis, T.N., Panagiotakos, D.B., Sergentanis, I.N., Kosti, R., and Scarmeas, N. (2013). Mediterranean diet, stroke, cognitive impairment, and depression: a meta-analysis. Ann. Neurol. 74: 580-591.

Rastmanesh, R., Beauchet, O., and Annweiler, C. (2012). Vitamin D deficiency and depression: causal relationship or artifact? Biofactors 38 317-319.

Rush, A.J., Trivedi, M.H., Wisniewski, S.R., Nierenberg, A.A., Stewart, J.W. Warden, D., Niederehe, G., Thase, M.E., Lavori, P.W., Lebowitz, B.D. McGrath, P.J., Rosenbaum, J.F., Sackeim, H.A., Kupfer, D.J., Luther, J., and Fava, M. (2006a). Acute and longer-term outcomes in depressed outpatients requiring one or several treatment steps: a STAR*D report. Am. J. Psychiatry. 163: 1905-1917.

Rush, A.J., Trivedi, M.H., Wisniewski, S.R., Stewart, J.W., Nierenberg, A.A. Thase, M.E., Ritz, L., Biggs, M.M., Warden, D., Luther, J.F., Shores-Wilson, K., Niederehe, G., and Fava, M. (2006b). Bupropion-SR, sertraline, or venlafaxine-XR after failure of SSRIs for depression. N. Engl. J. Med. 354: 1231-1242.

Shaffer, J.A., Edmondson, D., Wasson, L.T., Falzon, L., Homma, K., Ezeokoli, N., Li, P., and Davidson, K.W. (2014). Vitamin D supplementation for depressive symptoms: a systematic review and meta-analysis of randomized controlled trials. Psychosom. Med. 76: 190-196.

Spedding, S. (2014). Vitamin D and depression: a systematic review and meta-analysis comparing studies with and without biological flaws. Nutrients 6: 1501-1518.

Tolppanen, A.-M., Fraser, A., Fraser, W.D., and Lawlor, D.A. (2012). Risk factors for variation in 25-hydroxyvitamin D3 and D2 concentrations and vitamin D deficiency in children. J. Clin. Endocrinol. Metab. 97: 1202-1210.

Lázaro Tomé, A., Reig Cebriá, M.J., González-Teruel, A., Carbonell-Asíns, J.A., Cañete Nicolás, C., and Hernández-Viadel, M. (2021). Efficacy of vitamin $D$ in the treatment of depression: a systematic review and meta-analysis. Actas Esp. Psiquiatr. 49: 12-23.

Vieth, R. (2004). Why "Vitamin D" is not a hormone, and not a synonym for 1,25-dihydroxy-vitamin D, its analogs or deltanoids. J. Steroid Biochem. Mol. Biol. 89-90: 571-573.

Wacker, M., and Holick, M.F. (2013). Vitamin D - effects on skeletal and extraskeletal health and the need for supplementation. Nutrients 5 : 111-148.

Wang, J., Liu, N., Sun, W., Chen, D., Zhao, J., and Zhang, W. (2018). Association between vitamin $\mathrm{D}$ deficiency and antepartum and postpartum depression: a systematic review and meta-analysis of longitudinal studies. Arch. Gynecol. Obstetr. 298: 1045-1059.

Wang, T.J., Zhang, F., Richards, J.B., Kestenbaum, B., van Meurs, J.B., Berry, D., Kiel, D.P., Streeten, E.A., Ohlsson, C., Koller, D.L., Peltonen, L., Cooper, J.D., O'Reilly, P.F., Houston, D.K., Glazer, N.L., Vandenput, L., Peacock, M., Shi, J., Rivadeneira, F., McCarthy, M.I., Anneli, P., de Boer, I.H., Mangino, M., Kato, B., Smyth, D.J., Booth, S.L., Jacques, P.F., Burke, G.L., Goodarzi, M., Cheung, C.-L., Wolf, M., Rice, K., Goltzman, D., Hidiroglou, N., Ladouceur, M., Wareham, N.J., Hocking, L.J. Hart, D., Arden, N.K., Cooper, C., Malik, S., Fraser, W.D., Hartikainen, A.-L., Zhai, G., Macdonald, H.M., Forouhi, N.G., Loos, R.J.F., Reid, D.M., Hakim, A., Dennison, E., Liu, Y., Power, C., Stevens, H.E., Jaana, L., Vasan, R.S., Soranzo, N., Bojunga, J., Psaty, B.M., Lorentzon, M. Foroud, T., Harris, T.B., Hofman, A., Jansson, J.-O., Cauley, J.A., Uit- 
terlinden, A.G., Gibson, Q., Järvelin, M.-R., Karasik, D., Siscovick, D.S., Econs, M.J., Kritchevsky, S.B., Florez, J.C., Todd, J.A., Dupuis, J., Hyppönen, E., and Spector, T.D. (2010). Common genetic determinants of vitamin $D$ insufficiency: a genome-wide association study. Lancet. 376: 180-188.

World Health Organization. (2008). The Global burden of disease: 2004 update. World Health Organization, Geneva, Switzerland.
Zanello, S.B., Jackson, D.M., and Holick, M.F. (1999). An immunocytochemical approach to the study of beta-endorphin production in human keratinocytes using confocal microscopy. Ann. N. Y. Acad. Sci. 885: 85-99.

Zhao, G., Ford, E.S., Li, C., and Balluz, L.S. (2010). No associations between serum concentrations of 25 -hydroxyvitamin $D$ and parathyroid hormone and depression among US adults. Br. J. Nutr. 104: 1696-1702. 